\title{
Early Anastomotic Repair in the Rat Intestine is Affected by Transient Preoperative Mesenteric Ischemia
}

\author{
L. A. E. Posma • R. P. Bleichrodt • R. M. L. M. Lomme • \\ B. M. de Man • H. van Goor • T. Hendriks
}

Received: 14 January 2009 / Accepted: 28 January 2009 /Published online: 26 February 2009

(C) The Author(s) 2009. This article is published with open access at Springerlink.com

\begin{abstract}
Introduction During bowel surgery, perioperative blood loss and hypotension can lead to transient intestinal ischemia. Recent preclinical studies reveal that the strength of intestinal anastomoses can be compromised after reperfusion. So far, this phenomenon has not been investigated in the very first days of healing when wound strength is lowest.

Material and Method Ischemia was induced in rats by clamping both the superior mesenteric artery and ileal branches for $30 \mathrm{~min}$. Immediately after declamping, anastomoses were constructed in both terminal ileum and descending colon. The same was done in control groups after sham-ischemia. Anastomotic bursting pressure and breaking strength were measured immediately after operation (day 0) and after 1, 2, or 3 days. Anastomotic hydroxyproline content, gelatinase activity, and histology were analyzed.

Results and Discussion In ileal anastomoses, at day 1, both the breaking strength and bursting pressure were significantly $(p<0.05)$ lower in the ischemic group, while at day 2, this was the case for the bursting pressure only. In the colon, the bursting pressure in the ischemic group was lower at day 1. Anastomotic hydroxyproline content remained unchanged. Increased presence of the various gelatinase activities was found in ileum only at day 0 and in colon at days 1 and 2 . Histological mucosal damage was found in ischemia-reperfusion groups.

Conclusion Transient mesenteric ischemia can negatively affect anastomotic strength during the very first days of healing, even if the tissue used for anastomotic construction looks vital.
\end{abstract}

Keywords Anastomosis $\cdot$ Healing $\cdot$ Intestine $\cdot$ Ischemia $\cdot$ Reperfusion injury

\section{Introduction}

Anastomotic dehiscence remains a feared complication in gastrointestinal surgery, and diminishing its frequency, if not preventing it completely, constitutes a formidable challenge. A multitude of local factors and systemic conditions have been causally related to its occurrence, ${ }^{1}$ and research into the underlying mechanisms is mandatory

L. A. E. Posma • R. P. Bleichrodt • R. M. L. M. Lomme •

B. M. de Man $\cdot$ H. van Goor $\cdot$ T. Hendriks $(\triangle)$

Department of Surgery,

Radboud University Nijmegen Medical Center,

PO Box 9101, 6500 HB Nijmegen, The Netherlands

e-mail: t.hendriks@chir.umcn.nl in order to provide a sound basis for optimal clinical treatment of the patients needing resection and anastomosis of the intestine.

Uninterrupted wound healing requires oxygen. Essential features of the repair sequence depend on adequate woundtissue oxygenation. ${ }^{2}$ In fact, impaired perfusion of the splanchnic system most likely is a substantial factor in an number of conditions that are believed to increase the risk for anastomotic dehiscence. Anastomotic leak related to ischemia is a source of significant morbidity and mortality in gastrointestinal surgery. ${ }^{3}$ Experimental data unequivocally show persisting ischemia to impair the development of anastomotic strength. ${ }^{4,5}$

During bowel surgery, perioperative blood loss and hypotension can lead to transient intestinal ischemia. Events caused by reperfusion constitute an additional danger to tissues, both locally and systemic, resulting in damage that frequently exceeds the original ischemic 
insult. ${ }^{6}$ Recent preclinical studies have established that the strength of intestinal anastomoses can be compromised if reperfusion after a transient period of ischemia precedes intestinal resection and anastomosis. This effect occurs both in the locally affected area ${ }^{7,8}$ but also if the anastomosis is constructed at a distance. . $^{9,10}$

So far, this phenomenon has been investigated from 3 days after operation onwards, and experiments aimed at preventing this negative effect are mostly conducted at a single time point, often after 6 or 7 days. In a preceding comprehensive study, we have demonstrated a profound negative effect of transient mesenteric ischemia on the development of anastomotic strength from 3 days after operation onwards. ${ }^{11}$ As yet, no data are available on the very first inflammatory phase of anastomotic healing, where wound strength is at its lowest and presumably the risk of dehiscence at its highest. This study describes the effects of ischemia-reperfusion (IR) on anastomotic strength during the early postoperative period, from immediately after construction to the third day. In this phase, wound strength depends on the suture-anchoring capacity of the existing extracellular matrix. The quality of the matrix can be affected by the presence of proteolytic enzymes, the matrix metalloproteinases (MMPs), which are essential to the repair sequence. ${ }^{12}$ Since both MMP-2 and, especially, MMP-9 are upregulated during intestinal healing $^{13,14}$ and are believed to contribute to reperfusion injury in the gut, ${ }^{15,16}$ their activity in anastomotic tissue has also been examined.

\section{Material and Methods}

Animals

Male Wistar rats ( $n=112$; mean weight, $280 \mathrm{~g}$; Harlan BV, Horst, The Netherlands) were allowed to become accustomed to laboratory conditions for 1 week before experimental use. They were housed two per cage under specified pathogen-free conditions with free access to water and standard rodent food (Hope Farms, Woerden, The Netherlands). The study was approved by the Animal Ethics Review Committee of the Radboud University Nijmegen.

\section{Study Design}

In experimental groups (IR, $n=56$, four subgroups of 14 each), animals were subject to ischemia (see below) before anastomotic construction. In control groups $(C, n=56$, four subgroups of 14 each), anastomosis was performed without previous ischemia. Animals were killed either immediately after anastomotic construction (day 0) or at the first, second, or third postoperative day. From each subgroup, three animals were used for histological analysis, and 11 animals were used for measuring anastomotic strength and biochemical parameters.

\section{Operative Procedures}

All rats were anesthetized by using isoflurane (Abbott Laboratories, Queensborough, UK) in a mixture of oxygen and nitrous oxide. Procedures were performed under semisterile conditions, using an operation microscope (Carl Zeiss, Oberkochen, Germany).

In the experimental (IR) groups, the superior mesenteric artery (SMA) was dissected free and occluded just distal to its origin with a microvascular clamp (S \& T, Neuhausen am Rheinfall, Switzerland). Additionally, collateral circulation was interrupted by clamping ileal branches in the mesentery. Ischemia lasted $30 \mathrm{~min}$. In the control (C) groups, the SMA and ileal branches were dissected free but not occluded. After releasing the clamps, a $2-\mathrm{cm}$ resection was performed at the distal ileum, $15 \mathrm{~cm}$ proximal to the cecum. Continuity was restored by constructing an end-toend anastomosis with eight single-layer, inverting, interrupted 8-0 Ethilon ${ }^{\circledR}$ (Ethicon, Norderstedt, Germany) sutures. The same procedure was carried out in the descending colon, $3 \mathrm{~cm}$ proximal to the peritoneal reflection. This way, anastomoses were constructed in the experimental groups in parts of the bowel that had been ischemic (ileum) or had experienced normal perfusion (descending colon). The abdomen was closed, using a continuous 3-0 Vicryl ${ }^{\circledR}$ (Ethicon, Norderstadt, Germany) suture for the musculofascial layer and staples for the skin. During operations, body temperature was kept at $38^{\circ} \mathrm{C}$ using a heating pad. Temperature, heart rate, and peripheral oxygen saturation were monitored. The intestines were covered with gauze pads soaked with $0.9 \% \mathrm{NaCl}$ to minimize desiccation. To compensate for fluid loss, $10 \mathrm{ml}$ of $0.9 \% \mathrm{NaCl}$ was administered subcutaneously during the operation. Postoperative analgesia was performed with buprenorphine, $0.02 \mathrm{mg} / \mathrm{kg}$ subcutaneously, twice daily for 2 days. Animals were weighed daily and observed for signs of illness.

All operative procedures were performed by the same investigator (LAEP).

\section{Anastomotic Strength}

Animals were anesthetized and killed by intracardiac puncture. A relaparotomy was performed, and the peritoneal cavity was explored for the presence of adhesions or dehiscence. Segments of approximately $4 \mathrm{~cm}$ in length containing the anastomosis in the middle were carefully resected, including surrounding tissues and adhesions. In order to measure bursting pressure, the segments were 
infused $(2 \mathrm{ml} / \mathrm{min}$ ) with normal saline containing methylene blue. The maximum pressure $(\mathrm{mmHg})$ recorded immediately before sudden loss of pressure was taken as the bursting pressure. The area under the curve was considered to represent the bursting energy. The site of rupture (within or outside the anastomotic line) was also noted. Subsequently, the segments were placed in a tensiometer, and the breaking strength (in gram) was measured. This procedure, which analyses both parameters for wound strength within the same anastomotic segment, has been validated before. ${ }^{17}$ Then the anastomotic segments were cleaned from adhering tissue and debris. A 5-mm sample containing the anastomosis in the middle was frozen in liquid nitrogen and stored at $-80^{\circ} \mathrm{C}$ until further processing.

\section{Biochemical Analysis}

After lyophilization, tissue samples were weighed, pulverized, and lyophilized again. The hydroxyproline content, as a measure of the collagen content, was measured by high-performance liquid chromatography after hydrolysis with $6 \mathrm{~N}$ hydrochloric acid and derivatization with dabsyl chloride. Both hydroxyproline concentration $(\mu \mathrm{g} / \mathrm{mg}$ tissue) and hydroxyproline content ( $\mu \mathrm{g} / 5 \mathrm{~mm}$ tissue) were quantitated.

Preparation of tissue extracts and procedures for quantitative gelatin zymography have been described extensively before. ${ }^{18}$ The various gelatinase activities, representing MMP-2 and MMP-9, were quantitated on the basis of lyzed area and expressed as arbitrary units. Collagenase type 1 (from Clostridium histolyticum, Sigma Chemical, St Louis, MO, USA) was electrophoresed on each gel as an internal standard for in-between comparison of values obtained on different gels. The presence of true MMP activity was confirmed by adding $10 \mathrm{mM}$ ethylenediaminetetraacetic acid or 1,10 phenanthroline to the buffers used after electrophoresis.

\section{Histology}

Intestinal samples of approximately $1-\mathrm{cm}$ length containing the anastomosis in the middle were carefully resected en bloc, opened at the mesenteric side, and washed gently in $0.9 \% \mathrm{NaCl}$. They were spread out and immobilized, and the samples were immediately fixed in 4\% $(v / v)$ phosphatebuffered formaldehyde, $\mathrm{pH}$ 7.3. Each anastomosis was divided into two or three longitudinal strips. Specimens were dehydrated and embedded in paraffin. Sections of $4 \mu \mathrm{m}$ in thickness were stained with hematoxylin and eosin. Sections were analyzed in a blinded fashion using a binocular light microscope. Histological parameters such as epithelial damage, necrosis, and presence of neutrophils were assessed.
Statistics

Differences over time within either $\mathrm{C}$ or IR groups were tested for significance using an analysis of variance (ANOVA) and, if indicated, a Tukey-Kramer post test. Differences between $\mathrm{C}$ and IR groups were analyzed using a one- (strength) or two-tailed (MMPs) unpaired $t$ test. Use, by exception, of any other test is mentioned in the text. Differences with $p$ value $<0.05$ were considered significant.

\section{Results}

\section{General}

SMA occlusion and interruption of the collateral circulation resulted in diminished pulsations in the mesentery and pale coloring of the ileum and ascending colon. These phenomena were reversed after circulation was restored by releasing the clamps. Heart rate, temperature, and peripheral oxygen saturation remained constant during the procedure.

No premature deaths occurred in the control group and four $(7 \%, \mathrm{~ns})$ in the IR group, all during the first $24 \mathrm{~h}$ after operation. Except for one animal that showed signs of generalized peritonitis, no obvious cause of death could be established.

All animals lost weight after operation. At day 3, the average relative weight, as a percentage of preoperative weight, was $92.5 \%$ (SD, 2.6) in the control group and $89.5 \%$ (2.9) in the IR group $(p=0.059)$. At necropsy, no overt signs of complications were found in any of the 56 control animals. In the 52 animals from the IR groups that completed the experiment, signs of ileus and intra-abdominal abscesses were each seen in four (different) animals. Furthermore, obvious signs of anastomotic dehiscence were observed in another four animals $(8 \%, p=0.050)$.

\section{Anastomotic Strength}

During measurements of anastomotic strength, the site of tissue disruption was always within the suture line. In the ileum, anastomotic strength diminishes immediately after construction (Fig. 1). Analyzing the four control groups together, this effect was significant for the bursting pressure (ANOVA, $p=0.0095)$ and breaking strength $(p<0.0001)$ but not for the breaking energy $(p=0.0609)$. Within the IR groups, all parameters showed extreme significance $(p<0.0001)$. The relative loss of strength between day 0 and 1 was invariably greater in the IR groups: The average bursting pressure was reduced by $38 \%$ in the controls and by $71 \%$ in the IR group. The same was true for the bursting energy, $36 \%$ vs $62 \%$, and the breaking strength, $47 \%$ vs 

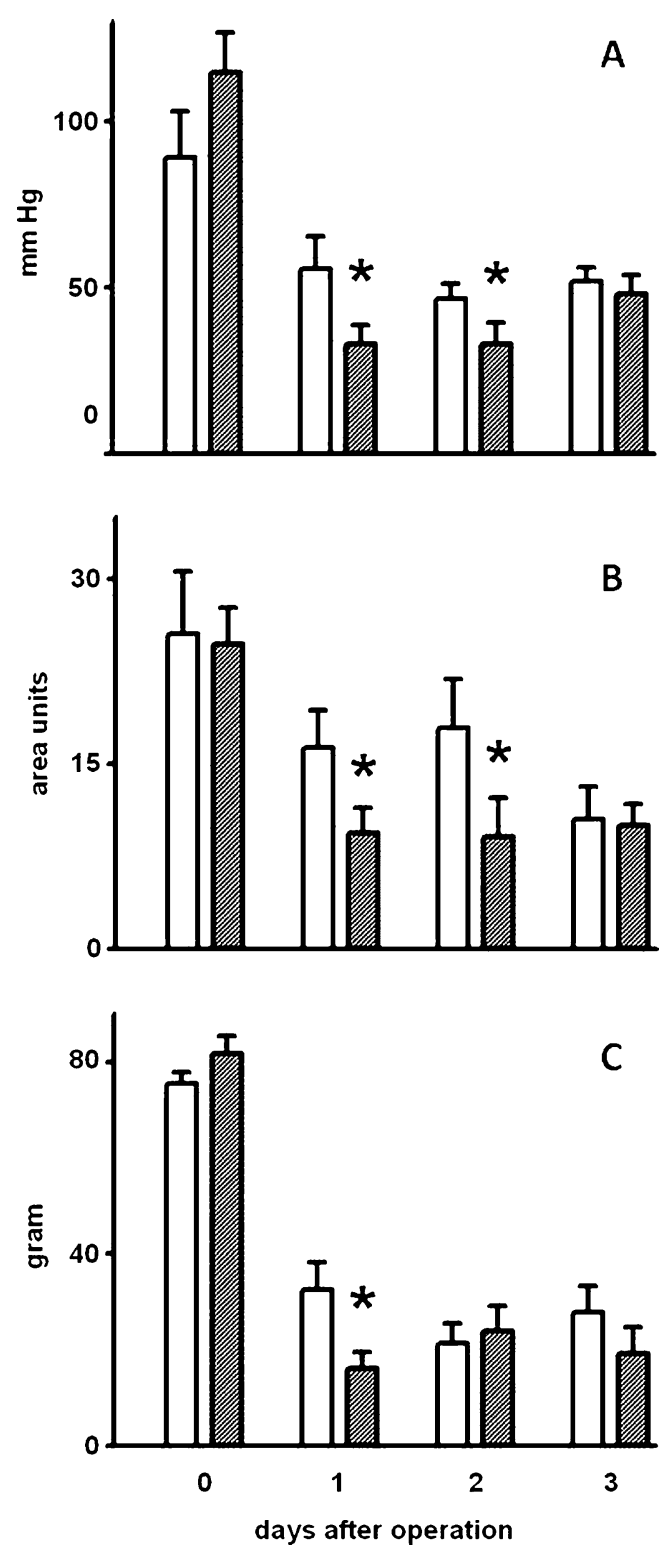

Figure 1 Anastomotic strength in the ileum. Columns represent mean values + SEM for control (open bars) and IR (striped bars) groups. Results are given for the bursting pressure (a), the bursting energy (b), and the breaking strength (c). ${ }^{*} p<0.050$ vs control group.

$80 \%$. As a result, anastomotic strength in the IR group was significantly $(p<0.05)$ lower than in the control group $24 \mathrm{~h}$ after surgery. With regard to the bursting pressure, this negative effect persisted another $24 \mathrm{~h}$ (day 2). Although the mean breaking strength at day 3 was $30 \%$ lower in the IR group, this difference failed to reach significance $(p=0.12)$.

The loss of wound strength over time, observed in the ileum, did not occur in the colon (Fig. 2). Still, a degree of reperfusion injury was also observed at this remote site since the bursting pressure in colonic anastomoses was significantly lower in the IR group than the controls at day 1 after operation. No differences were found for the breaking strength (not shown).
Biochemistry and Histology

Hydroxyproline levels, expressed as both the hydroxyproline concentration $(\mu \mathrm{g} / \mathrm{mg}$ dry tissue) and content $(\mu \mathrm{g} / 5-\mathrm{mm}$ tissue), were analyzed as a measure for collagen content in the anastomosis. In the ileal anastomoses, no significant (ANOVA) changes with time were found in either control or IR groups (Table 1). In addition, no differences were observed at any time point between control and IR groups. The same was true for colonic anastomoses (data not shown).

Quantitative gelatin zymography allows the separate analysis of the various forms of the gelatinases present in tissue extracts (Fig. 3 a, b). The active and latent forms of both MMP-2 and MMP-9 were measured, and their total activity within the $(5 \mathrm{~mm})$ anastomotic segment was calculated. In the ileal anastomoses, both forms of the MMPs exhibited significant $(p<0.05$, Kruskal-Wallis) changes over time (Fig. 4). In the controls, both active and proMMP-9 were highest at day 1 . This pattern was changed in the IR groups. Immediately after construction, both active and proMMP-9 activities were significantly higher in the IR group than in the controls. The same was true for proMMP-9 at day 3, but here, active MMP-9 was lowest in the IR group. MMP-2 activities were lowest at day 0 , where the active form was increased in the IR group. Subsequently, both MMP-2 forms
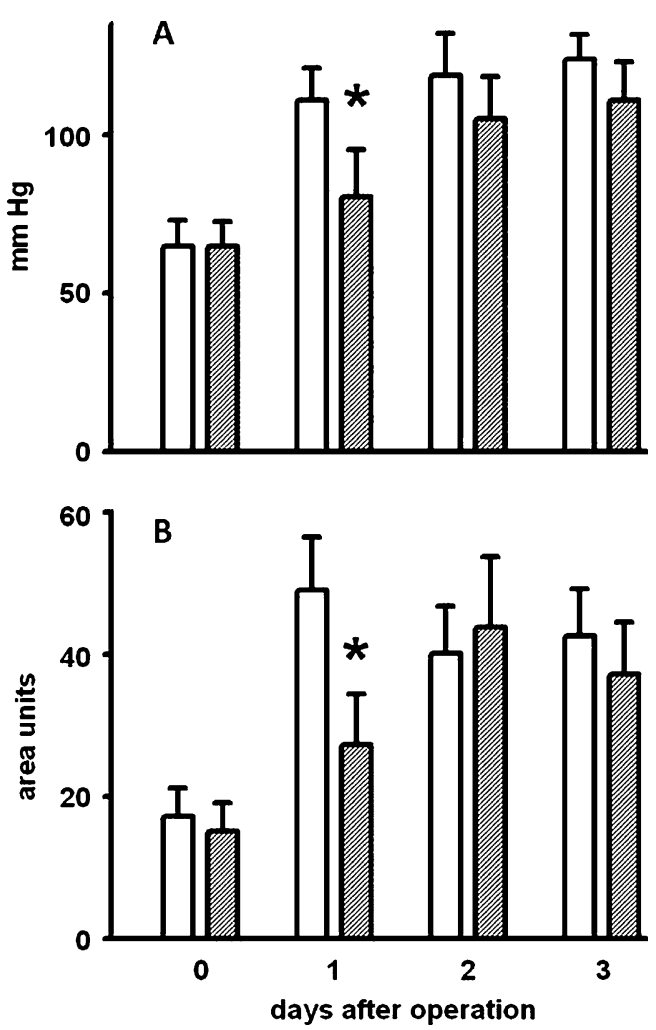

Figure 2 Anastomotic strength in the colon. Columns represent mean values + SEM for control (open bars) and IR (striped bars) groups. Results are given for the bursting pressure (a) and the bursting energy (b). ${ }^{*} p<0.050$ vs control group. 
Table 1 Anastomotic hydroxyproline in the ileum

\begin{tabular}{lclll}
\hline & Day 0 & Day 1 & Day 2 & Day 3 \\
\hline $\begin{array}{l}\text { Concentration }(\mu \mathrm{g} / \mathrm{mg}) \\
\text { Controls }\end{array} 10.0(2.9)$ & $8.2(4.1)$ & $7.6(2.6)$ & $5.9(2.4)$ \\
IR & $9.1(3.1)$ & $9.2(3.3)$ & $7.1(2.1)$ & $7.9(2.4)$ \\
Content $(\mu \mathrm{g} / 5 \mathrm{~mm})$ & & & \\
Controls & $147(73)$ & $131(54)$ & $149(47)$ & $127(36)$ \\
IR & $119(42)$ & $129(37)$ & $130(43)$ & $191(65)$ \\
\hline
\end{tabular}

Data represent means and (in brackets) SD. No significant differences between control and IR groups.

were higher, and a significant difference between control and IR groups was only observed for proMMP-2 at day 2 . The MMP activities in colonic anastomoses are depicted in Fig. 5. For MMP-9, hardly any difference was found between control and experimental groups. Interestingly, both latent and active MMP-2 activities were significantly higher in the IR groups at days 1 and 2, while at day 3 , the opposite trend was observed.

Histological analysis immediately after anastomotic construction, at day 0 , revealed mucosal damage in the IR groups, with elevation of the epithelial layer from the lamina propria and denuding and loss of height of the villi. These effects of ischemia and reperfusion gradually subsided during the first $24 \mathrm{~h}$. Except for these differences, microscopic architecture of the anastomoses appeared to be similar in control and IR groups.

\section{Discussion}

If an anastomosis is constructed in an intestinal segment, immediately after tissue perfusion has been restored following

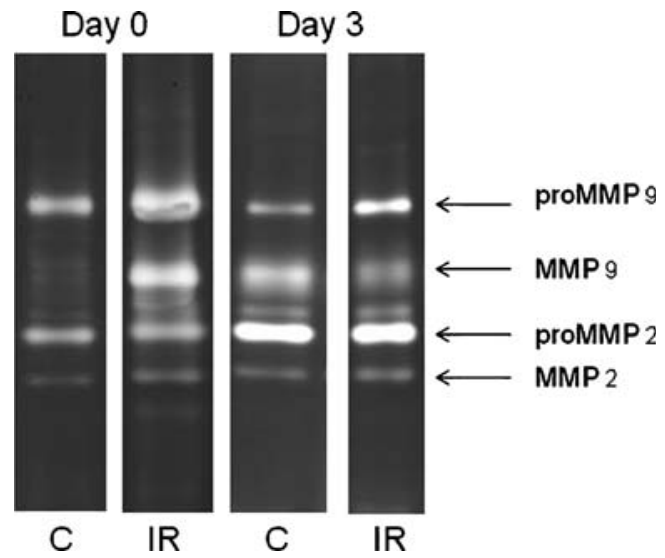

Figure 3 MMP activity in ileal anastomoses as demonstrated by gelatin zymography. Representative samples of tissue extracts as used for quantitation of the pro- and active forms of MMP-2 and MMP-9, which are separated by molecular weight on a gelatin gel. Samples from the control $(C)$ and IR groups at both days 0 and 3 .
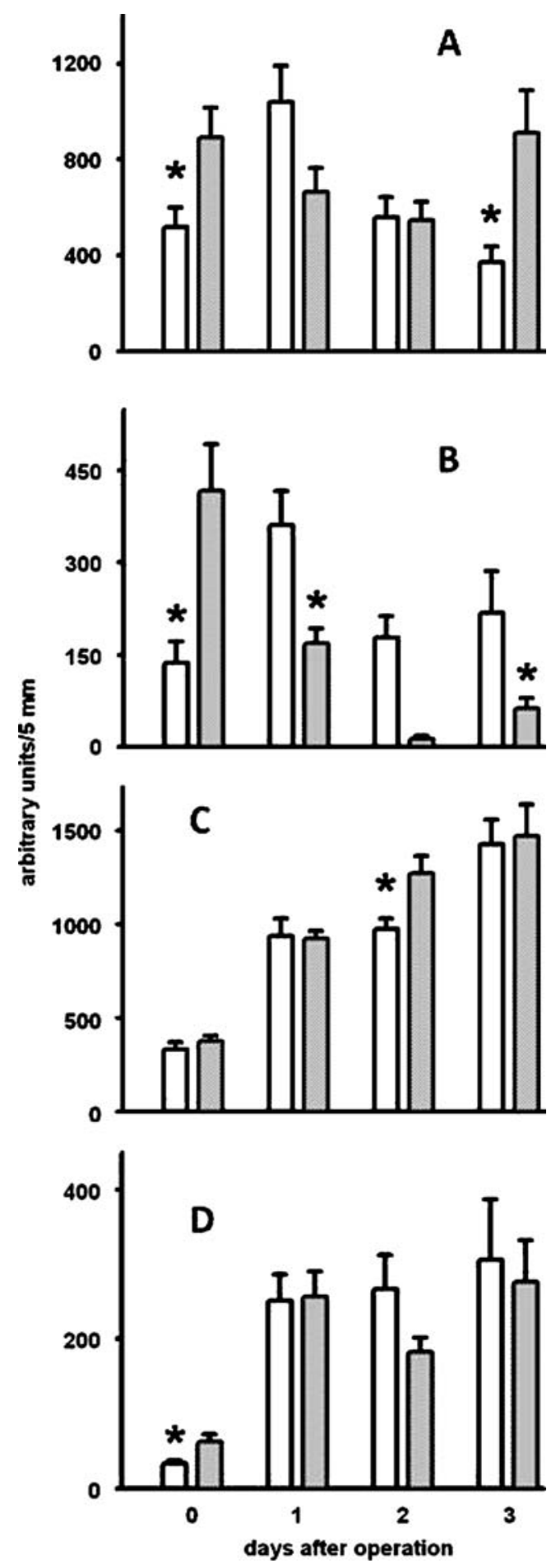

Figure $4 \mathrm{MMP}$ activity in ileal anastomoses. Columns represent mean values+SEM for control (open bars) and IR (striped bars) groups. Data represent total activities, in arbitrary units, per 5-mm segment for proMMP-9 (a), MMP-9 (b), proMMP-2 (c) and MMP-2 (d). ${ }^{*} p<0.050$ for differences between control and IR group at any of the time points. 

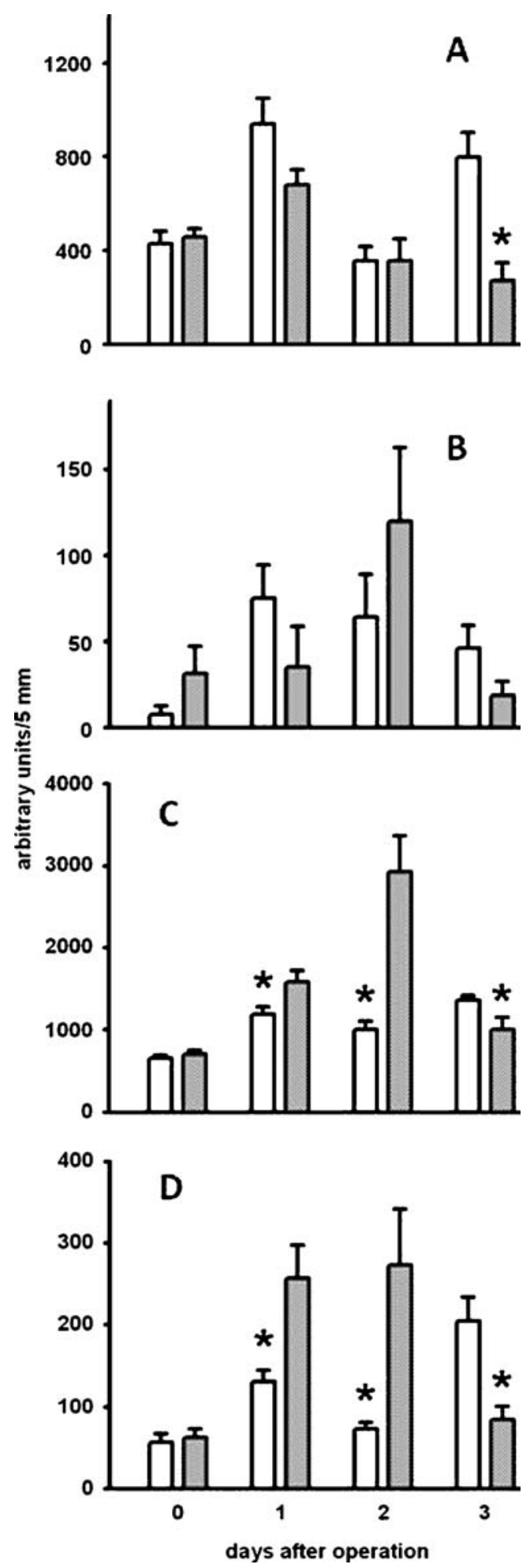

Figure 5 MMP activity in colonic anastomoses. Columns represent mean values + SEM for control (open bars) and IR (striped bars) groups. Data represent total activities, in arbitrary units, per 5-mm segment for proMMP-9 (a), MMP-9 (b), proMMP-2 (c), and MMP-2 (d). ${ }^{*} p<0.050$ for differences between control and IR group at any of the time points. a period of intestinal ischemia, wound strength is compromised during the very first days after operation. The data reported now are the first on such an effect being present in the early period of anastomotic healing. Together with those from our prior study, ${ }^{11}$ they demonstrate that IR-related injury results in loss of wound strength over the entire first postoperative week, thus affecting both the inflammatory and proliferation phases of the healing process.

Clamping and declamping of the SMA, together with its ileal branches in the mesentery, is an established method to interrupt mesenterial blood flow to the ileum and the ascending colon. ${ }^{19}$ Although it induces deep ischemia, this procedure, even if followed by anastomotic construction, shows a 93\% survival rate (in the IR group) and thus provides a good model to study effects of reperfusion injury on wound repair.

The primary outcome parameter for anastomotic healing is wound strength, which can be measured as both bursting pressure and breaking strength, even in the same animal. ${ }^{17}$ If the tissue ruptures within the true anastomotic line, as is the case within the time period under investigation here, the former represents the ability of the wound to withstand intraluminal pressure and the latter its ability to resist forces applied longitudinally. Both type of forces are presumably at work during intestinal movement, and therefore, both parameters are very relevant, although they may behave independently. ${ }^{20}$ Any reduction in either of the two may be taken as a sign of impaired healing. Thus, IR has a significant negative effect on anastomotic strength: if the anastomosis is constructed in ileal tissue, which actually has suffered an ischemic event, wound strength is compromised at 24 and $48 \mathrm{~h}$ after operation. If the anastomosis is constructed at a distance, in the descending colon, systemic effects of reperfusion result in a lower wound strength after $24 \mathrm{~h}$. As a consequence, the risk of anastomotic failure is enhanced: Signs of dehiscence are repeatedly observed in the IR group and not in the controls.

If the results from the present and preceding ${ }^{11}$ studies, covering the entire first postoperative week, are taken together, they demonstrate that mesenteric IR consistently lowers anastomotic strength from the first postoperative day onwards. The first days of healing are characterized by the inflammatory phase: From approximately 3 days after operation onwards, the proliferative phase becomes increasingly important. ${ }^{1}$ Presumably, wound strength in the first few days depends on the existing extracellular matrix and only later on the newly deposited collagen. Thus, it could very well be that the mechanism causing loss of strength at day 2 is entirely different to the one causing the same phenomenon at day 7 . Such a difference seems not unlikely because of the fact that, during the early days, the bursting pressure is clearly affected, while this is less so if anastomoses are examined from day 3 onwards. ${ }^{11}$ Very 
recently, a number of studies have reported treatments to prevent loss of anastomotic strength after reperfusion injury, almost invariably analyzed at least 6 days after operation. ${ }^{2,5,10,21,22}$ The current results emphasize the need to also investigate the first period of healing, since different pathways may be responsible for delayed repair. Furthermore, investigators should be well advised to measure the parameter for anastomotic strength, which is most sensitive to reperfusion injury.

By anchoring the sutures, the extracellular matrix determines wound strength in the period investigated in this study, well before any deposition of newly formed collagen occurs within the wound area. ${ }^{23}$ The hydroxyproline measurements, admittedly a relatively insensitive way to estimate the anastomotic collagen content, are not suggestive for increased matrix degradation in the IR groups. Still, local action of MMPs could result in focused and limited degradation, ${ }^{24}$ for instance in areas next to sutures, thereby weakening the wound. Still, our data on MMP-2 and MMP-9 do not yield a consistent picture of upregulation after IR. Immediately after anastomotic construction (day 0) in the ileum, MMP-9 and active MMP-2 activities are greater in the IR groups, which is consistent with earlier findings in the rat intestine after a 90-min reperfusion. ${ }^{25}$ However, this effect does not persist, and at later time points, active MMP-9 is even reduced in the IR groups. Remarkably, in the colonic anastomoses, MMP-2 activities after IR are enhanced at days 1 and 2 but reduced at day 3. It remains to be determined if a relatively short period of enhanced proteolytic activity can induce enough local damage of the extracellular matrix to result in a lasting period of reduced wound strength. Any definite proof of a causal role of MMPs in lowering wound strength can only come from studies using specific inhibitors.

Mesenteric ischemia is a common event in surgery. During bowel surgery, intraoperative blood loss or cardiopulmonary events may cause hypoperfusion and relative intestinal ischemia, which can lead to impaired healing. ${ }^{26}$ In fact, IR injury of the intestine is a significant problem in a multitude of situations, such as abdominal aortic aneurysm surgery, small bowel transplantation, cardiopulmonary bypass, strangulated hernias, and neonatal necrotizing enterocolitis. It can also occur in septic and hypovolemic shock. ${ }^{27}$

The present data have been obtained in an animal model. As always, it remains to be proven that they are relevant to the clinical situation also. Still, together with the existing literature, they show what the implications could be of deep but transient intestinal ischemia. Even when seemingly vital tissue is used for anastomotic construction, local healing may be compromised from the very first day onwards, ultimately leading to dehiscence. Bearing this in mind, it is apparent that studies aimed at establishing actual mechanisms and finding preventive measures are needed.
Open Access This article is distributed under the terms of the Creative Commons Attribution Noncommercial License which permits any noncommercial use, distribution, and reproduction in any medium, provided the original author(s) and source are credited.

\section{References}

1. Witte MB, Barbul A. Repair of full-thickness bowel injury. Crit Care Med 2003;31(Supp1 8):538-546. doi:10.1097/01. CCM.0000081436.09826.A4.

2. Enestvedt CK, Thompson SK, Chang EY, Jobe BA. Clinical review: healing in gastrointestinal anastomoses, part II. Microsurgery 2006;26:137-143. doi:10.1002/micr.20198.

3. Enestvedt CK, Hosack L, Winn SR, Diggs BS, Uchida B, O'Rourke RW, Jobe BA. VEGF gene therapy augments localized angiogenesis and promotes anastomotic wound healing: a pilot study in a clinically relevant animal model. J Gastrointest Surg 2008;12:1762-1770. doi:10.1007/s11605-008-0635-3.

4. Topçu O, Karaday K, Kuzu MA, Ulukent S, Erkek B, Alaçayir I. Enteral and intraluminal short-chain fatty acids improves ischemic left colonic anastomotic healing in the rat. Int J Colorectal Dis 2002;17:171-176. doi:10.1007/s003840100357.

5. Parra-Membrives P, Ruiz-Luque V, Escudero-Severín C, AguilarLuque J, Méndez-García V. Effect of pentoxifylline on the healing of ischemic colorectal anastomoses. Dis Colon Rectum 2007;50:369-375. doi:10.1007/s10350-006-0803-z.

6. Mallick IH, Yang W, Winslet MC, Seifalian AM. Ischemiareperfusion injury of the intestine and protective strategies against injury. Dig Dis Sci 2004;49:1359-1377. doi:10.1023/B: DDAS.0000042232.98927.91.

7. Kuzu MA, Köksoy C, Kale IT, Tanik A, Terzi C, Elhan AH. Reperfusion injury delays healing of intestinal anastomosis in a rat. Am J Surg 1998;176:348-351. doi:10.1016/S0002-9610 (98)00198-6.

8. Wasserberg N, Tzakis AG, Santiago SF, Ruiz P, Salgar SK. Anastomotic healing in a small bowel transplantation model in the rat. World J Surg 2004;28:69-73. doi:10.1007/s00268-0037028-2.

9. Kologlu M, Yorganci K, Renda N, Sayek I. Effect of local and remote ischemia-reperfusion injury on healing of colonic anastomoses. Surgery 2000;128:99-104. doi:10.1067/msy.2000.107414.

10. Teke Z, Sacar M, Yenisey C, Atalay AO, Bicakci T, Erdem E. Activated protein $\mathrm{C}$ prevents deleterious effects of remote reperfusion injury caused by intestinal ischemia on wound healing in the left colonic anastomoses: an experimental study in the murine model. Am J Surg 2008;196:774-787. doi:10.1016/j. amjsurg.2007.09.039.

11. Posma LA, Bleichrodt RP, van Goor H, Hendriks T. Transient profound mesenteric ischemia strongly affects the strength of intestinal anastomoses in the rat. Dis Colon Rectum 2007;50:1070-1079. doi:10.1007/s10350-006-0822-9.

12. Gill SE, Parks WC. Metalloproteinases and their inhibitors: regulators of wound healing. Int $\mathrm{J}$ Biochem Cell Biol 2008;40:1334-1347. doi:10.1016/j.biocel.2007.10.024.

13. Savage FJ, Lacombe DL, Boulos PB, Hembry RM. Role of matrix metalloproteinases in healing of colonic anastomosis. Dis Colon Rectum 1997;40:962-970. doi:10.1007/BF02051206.

14. de Hingh IH, Lomme RM, van Goor H, Bleichrodt RP, Hendriks T. Changes in gelatinase activity in the gastrointestinal tract after anastomotic construction in the ileum or colon. Dis Colon Rectum 2005;48:2133-2141. doi:10.1007/s10350-005-0142-5.

15. Robinson EK, Kelly DP, Mercer DW, Kozar RA. Differential effects of luminal arginine and glutamine on metalloproteinase 
production in the postischemic gut. JPEN J Parenter Enteral Nutr 2008;32:433-438. doi:10.1177/0148607108319806.

16. Costantino G, Egerbacher M, Kolbe T, Karaghiosoff M, Strobl B, Vogl C, Helmreich M, Müller M. Tyk2 and signal transducer and activator of transcription 1 contribute to intestinal $\mathrm{I} / \mathrm{R}$ injury. Shock 2008;29:238-244.

17. de Waard JW, Wobbes T, de Man BM, van der Linden CJ, Hendriks T. Post-operative levamisole may compromise early healing of experimental intestinal anastomoses. Br J Cancer 1995;72:456-460.

18. Siemonsma MA, de Hingh IH, de Man BM, Lomme RM, Verhofstad AA, Hendriks T. Doxycycline improves wound strength after intestinal anastomosis in the rat. Surgery 2003;133:268-276. doi:10.1067/msy.2003.27.

19. Megison SM, Horton JW, Chao H, Walker PB. A new model for intestinal ischemia in the rat. J Surg Res. 1990;49:168-173. doi:10.1016/0022-4804(90)90257-3.

20. Mansson P, Zhang XW, Jeppsson B, Thorlacius H. Anastomotic healing in the rat colon: comparison between a radiological method, breaking strength and bursting pressure. Int J Colorectal Dis 2002;17:420-425. doi:10.1007/s00384-002-0392-9.

21. Teke Z, Aytekin FO, Kabay B, Yenisey C, Aydin C, Tekin K, Sacar M, Ozden A. Pyrrolidine dithiocarbamate prevents deleterious effects of remote ischemia/reperfusion injury on healing of colonic anastomoses in rats. World J Surg 2007;31:1835-1842. doi:10.1007/s00268-007-9106-3.
22. Colak T, Turkmenoglu O, Dag A, Polat A, Comelekoglu U, Bagdatoglu O, Polat G, Kanik A, Akca T, Aydin S. The effect of remote ischemic preconditioning on healing of colonic anastomoses. J Surg Res 2007;143:200-205. doi:10.1016/j. jss.2006.10.030

23. Verhofstad MHJ, Lange WP, van der Laak JAWM, Verhofstad AAJ, Hendriks T. Microscopic analysis of anastomotic healing in the intestine of normal and diabetic rats. Dis Colon Rectum 2001;44:423-431. doi:10.1007/BF02234744.

24. Agren MS, Andersen TL, Mirastschijski U, Syk I, Schiødt CB, Surve V, Lindebjerg J, Delaissé JM. Action of matrix metalloproteinases at restricted sites in colon anastomosis repair: an immunohistochemical and biochemical study. Surgery. 2006;140:72-82. doi:10.1016/j.surg.2005.12.013.

25. Rosario HS, Waldo SW, Becker SA, Schmid-Schonbein GW. Pancreatic trypsin increases matrix metalloproteinase- 9 accumulation and activation during acute intestinal ischemia-reperfusion in the rat. Am J Pathol. 2004;164:1707-1716.

26. Matthiessen P, Hallböök O, Rutegård J, Sjödahl R. Intraoperative adverse events and outcome after anterior resection of the rectum. Br J Surg. 2004;91:1608-1612. doi:10.1002/bjs.4530.

27. Mallick IH, Yang W, Winslet MC, Seifalian AM. Ischemiareperfusion injury of the intestine and protective strategies against injury. Dig Dis Sci. 2004;49:1359-1377. doi:10.1023/B: DDAS.0000042232.98927.91. 